\title{
Fractionation and characterisation of dietary fibre from
}

\section{blackcurrant pomace}

Kontogiorgos $^{\mathrm{a}^{*}}$

${ }^{a}$ Department of Biological Sciences, University of Huddersfield, HD1 3DH, UK

$22 *$ Corresponding author

23 Tel.: +44 1484472488

24 e-mail: v.kontogiorgos@hud.ac.uk 


\section{Abstract}

The potential of blackcurrant pomace as a raw material for the extraction of dietary fibre was evaluated using two pomaces one sourced from the UK and one from Poland.

31 A fractionation protocol was designed to isolate and subsequently quantify the soluble 32 and insoluble dietary fibre fractions. Blackcurrant pomace and isolated pectins, 33 hemicelluloses and celluloses were assessed by means of sugar compositional analysis, 34 spectroscopy, size exclusion chromatography and dilute solution viscometry. The blackcurrant pomaces presented considerable amounts of dietary fibre with soluble fibre ranging from $25-30 \% \mathrm{w} / \mathrm{w}$ and insoluble dietary fibre accounting for about $47 \%$ $\mathrm{w} / \mathrm{w}$ for both pomaces. Blackcurrant pomaces differed in the amount of extracted pectins with an almost two times higher pectin yield obtained from blackcurrant pomace sourced from Poland. The hemicellulosic polysaccharide content was $15 \% \mathrm{w} / \mathrm{w}$ whereas the amount of cellulosic fraction varied from 14-17\% w/w. Pectins isolated from both blackcurrant pomaces were LM pectins with a degree of esterification in the range of $11-38 \%$. The work has identified that dietary fibres obtained from blackcurrant pomace had desirable ratio of insoluble to soluble fibre and are a potential new source of dietary fibre. 
Abbreviations:

54 POMUK - pomace from UK

55 POMPOL - pomace from Poland

56 pIDFUK - pure insoluble dietary fibre from UK (fraction that was obtained after

57 extraction of acid-soluble and $\mathrm{Ca}^{2+}$-bound pectins)

58 pIDFPOL - pure insoluble dietary fibre from Poland

59 APUK - acid-soluble pectin isolated from POMUK

60 APPOL - acid-soluble pectin isolated from POMPOL

61 CBPUK - calcium-bound pectin isolated from POMUK

62 CBPPOL - calcium-bound pectin isolated from POMPOL

63 HEMUK - hemicellulose isolated from POMUK

64 HEMPOL - hemicellulose isolated from POMPOL

65 CELUK - cellulose isolated from POMUK

66 CELPOL - cellulose isolated from POMPOL

$67 \quad \mathrm{DF}-$ dietary fibre

68 SDF - soluble dietary fibre

69 IDF - insoluble dietary fibre

70 DE - degree of esterification

71 HBSS - hot buffer soluble solids

72 CHSS - chelator soluble solids

$73 \mathrm{HG}$ - homogalacturonan

74 RG-I - rhamnogalacturonan-I

75 GalA - galacturonic acid

76 MWCO - molecular weight cut-off

77 LM pectin - low-methylated pectin 


\section{Introduction}

Processing of fruits and vegetables results in a large amount of agricultural waste with significant potential for the recovery of functional materials. For instance, about $15 \%$ of grapes or $20 \%$ of soft berries used in winemaking or juice manufacturing are discarded in the form of pomace (Makris, Boskou, \& Andrikopoulos, 2007; Minjares-Fuentes, Femenia, Garau, Meza-Velazquez, Simal, \& Rossello, 2014a). Commonly, fruit or vegetable pomace is discarded (e.g. into soil or landfills), however, the pomace obtained after juice pressing could also be of great interest to food, pharmaceutical and cosmetic industries due to the high carbohydrate fraction that can be utilised as a source of dietary fibre (DF), structuring components and/or bioactive compounds (Femenia, 2007; Rohm, Brennan, Turner, Günther, Campbell, Hernando, Struck, \& Kontogiorgos, 2015; Quiles, Campbell, Struck, Rohm \& Hernando, 2016).

DFs are often carbohydrate polymers that are resistant to digestion and absorption in the human small intestine and undergo complete or partial fermentation in the human large intestine (DeVries, Camire, Cho, Craig, Gordon, Jones, Li, Lineback, Prosky, \& Tungland, 2001). DFs are classified based on their solubility in water into soluble fibre (e.g., pectin and some hemicelluloses) or insoluble fibre (e.g., cellulose or lignin). Adequate consumption of DF has been linked to diverse nutritional and health benefits. It has been shown that DFs from various sources have the capacity to regulate food intestinal transit, with concomitant benefits to health including reduced risks of diabetes, cardiovascular diseases and obesity (Kendall, Esfahani, \& Jenkins, 2010; Mann \& Cummings, 2009).

Generally, DFs derived from fruit and vegetable co-products contain a higher content of soluble DF (SDF) than those obtained from cereals, present insoluble-tosoluble fibre ratios in the range 1 to 3 that are technologically desirable (Larrauri, 1999; 
103 Vergara-Valencia, Granados-Pérez, Agama-Acevedo, Tovar, Ruales, \& Bello-Pérez,

104 2007) and therefore have superior functional properties (e.g., water holding or swelling

105 capacity, viscosity enhancement or gel formation). The presence of a soluble fibre

106 fraction in DF may provide improved physiological functions in addition to the

107 functionality provided by the insoluble DF (IDF) fraction. Moreover, fruit DF also

108 contains considerable amounts of various bioactive compounds (e.g., polyphenols) that

109 can provide additional health benefits (Struck, Plaza, Turner, \& Rohm, 2016). DF

110 content of wheat flour is limited to $2-4 \%$ and therefore incorporation of DF from

111 alternative sources such as whole grain cereals and fruits in food formulations could

112 increase the nutritional value of the final products (Jenkins, Kendall, \& Ransom, 1998;

113 Pelucchi, Talamini, Galeone, Negri, Franceschi, Dal Maso, Montella, Conti, \& La

114 Vecchia, 2004). The effectiveness of DF to deliver or promote health benefits depends

115 not only on intake but also on the source of DF and its structural and chemical

116 composition. In addition, the incorporation of DF into food requires a substantial

117 understanding of its chemical structure due to the interactions between DF and other

118 ingredients (e.g., gluten) that can considerably alter microstructure and acceptability 119 characteristics of the final product.

120 Blackcurrant (Ribes nigrum) is primarily used in juice manufacturing,

121 generating several thousand tonnes per annum of pomace with the potential for

122 recovery of novel functional DF. The application of modern extraction methods for

123 fractionation of blackcurrant pomace into its constituent components (pectin,

124 hemicellulose, cellulose and lignin) with specified chemical compositions and physical

125 properties might improve its functionality and promote the development of value-added

126 ingredients for human consumption. The premise of the current work is that

127 blackcurrant pomace, if characterised and fractionated appropriately, could be adopted 
128 by the food industry as a source of functional DF. Chemical composition and 129 macromolecular properties may vary depending on the blackcurrant cultivar, growth

130 conditions, climate, and processing steps, thus influencing the techno-functional (e.g.,

131 product stability) and bio-functional properties (e.g., digestion). The aims of this study,

132 therefore, were to fractionate and characterise the carbohydrate polymers present in

133 blackcurrant pomaces from two distinct regions (UK and Poland), with the goal to 134 evaluate in more general terms the potential of blackcurrant pomace as a raw material 135 for the production of functional DF fractions.

\section{2. Materials and methods}

\section{$137 \quad 2.1$ Materials}

138 Two dried blackcurrant pomaces (Ribes nigrum) consisting of stems, seeds and 139 exocarp were obtained from Lucozade-Ribena-Suntory (LRS, UK) and GreenField

140 Natural Ingredients (Warsaw, Poland). All analytical reagents and standards reported 141 in the experimental sections were purchased from Sigma-Aldrich (Poole, UK). Pectin 142 standards with $10 \%$ and $70 \%$ degree of esterification (DE) were obtained from CP 143 Kelco UK Ltd.

\section{$144 \quad 2.2$ Fibre fractionation}

145 Blackcurrant pomaces were milled to an average particle size of $<1 \mathrm{~mm}$ prior

146 to fibre extraction. The fractionation protocol of pectins, hemicelluloses, cellulose and

147 lignin is shown in Figure 1. Fractionation of pomace was performed using a batch 148 extraction approach (200 g of milled pomace) on a laboratory scale. Isolated pectins 149 and hemicelluloses were dialysed against distilled water in order to remove impurities

150 such as low molecular weight sugars and oligomers, amino acids, organic acids and 151 inorganic salts. Pectin and hemicellulose fractions were freeze-dried after dialysis for $152 \quad 24 \mathrm{~h}$. 


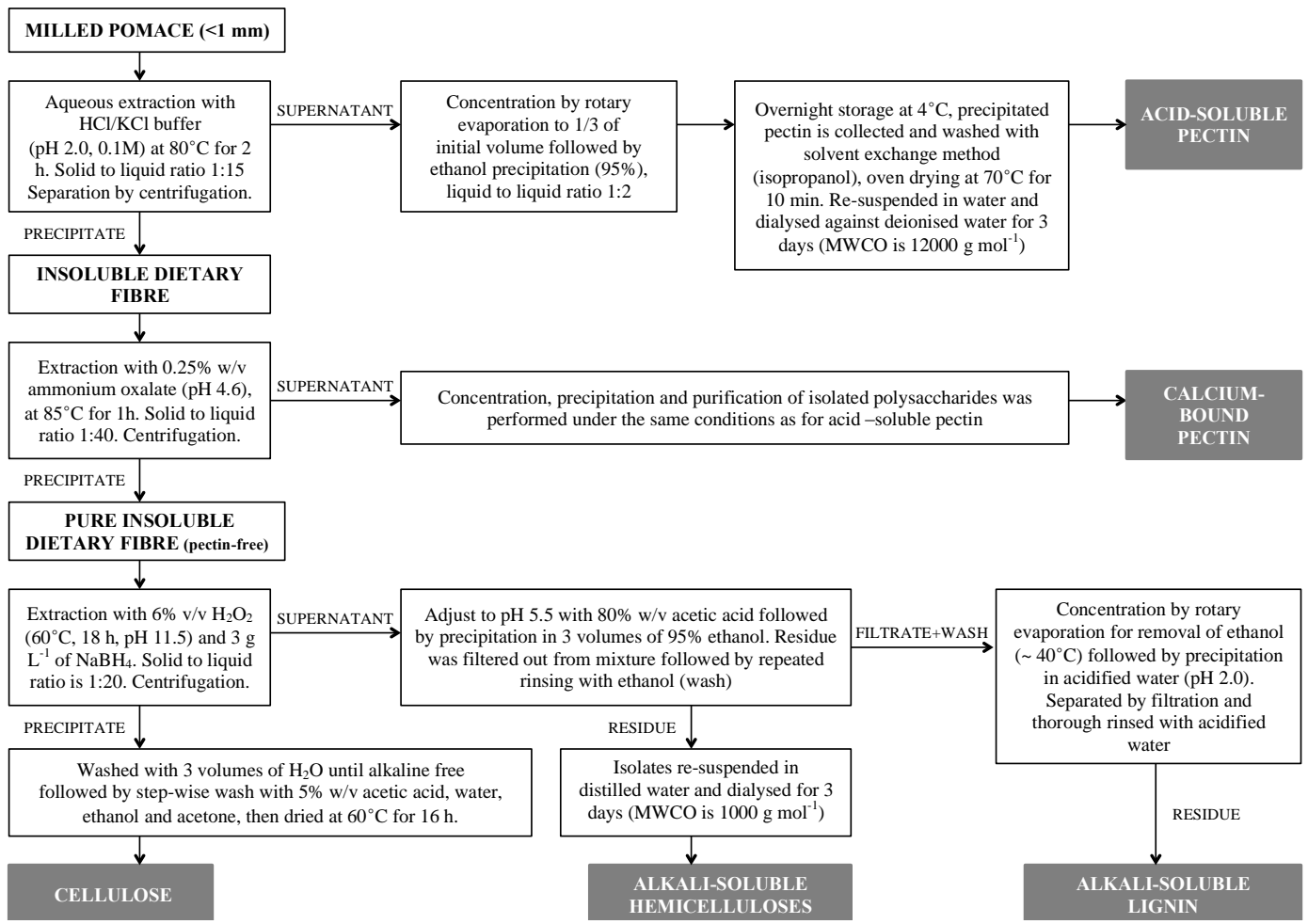

Figure 1. Sequential fractionation protocol of blackcurrant pomace into soluble and insoluble DFs. Five fractions were separated from the raw material including acidsoluble and calcium-bound pectins, celluloses, hemicelluloses and lignin.

\subsection{Characterisation of blackcurrant pomaces and DFs}

Proximate analysis (i.e., protein, ash, moisture, fat and carbohydrate) of blackcurrant pomaces was conducted by International Laboratory Services (ILS Limited, Derby, UK). Yields of pectin (acid-soluble and calcium-bound), hemicellulose, cellulose and alkali-soluble lignin were determined gravimetrically following the fractionation protocol. Klason lignin was determined in the following samples: pomaces, pure insoluble DF (pIDF) and isolated celluloses after a two-step Saeman hydrolysis with sulphuric acid (Englyst \& Cummings, 1988). Hydrolysis was performed as follows: $50 \mathrm{mg}$ of sample was pre-hydrolysed with $12 \mathrm{M} \mathrm{H}_{2} \mathrm{SO}_{4}$ for $1 \mathrm{~h}$ at $35{ }^{\circ} \mathrm{C}$ followed by dilution to $1 \mathrm{M} \mathrm{H}_{2} \mathrm{SO}_{4}$ by addition of $\mathrm{H}_{2} \mathrm{O}$ and boiling at $100{ }^{\circ} \mathrm{C}$ for $2 \mathrm{~h}$. The insoluble residue was filtered out of the mixture, dried at $102{ }^{\circ} \mathrm{C}$ and ashed for $4 \mathrm{~h}$ at $425^{\circ} \mathrm{C}$. The filtrate was collected and used for spectrophotometric determination 
171 of uronic acids by the $m$-hydroxydiphenyl method (Filisetti-Cozzi \& Carpita, 1991) in

172 pomaces, pIDF fractions and celluloses. Klason lignin was then calculated using:

$$
\operatorname{lignin}(\% \mathrm{w} / \mathrm{w})=\frac{\text { mass after drying }- \text { mass after ashing }}{\text { mass of sample before hydrolysis }} 100 \%
$$

174

The content of uronic acids in soluble DF fractions (i.e., acid-soluble pectin, calcium-bound pectin and hemicelluloses) was determined using the aforementioned $m$-hydroxydiphenyl method. Neutral sugars were analysed as alditol acetates after trifluoroacetic acid (TFA) hydrolysis in soluble and insoluble fractions. Soluble DF fractions (i.e., acid-soluble pectin, calcium-bound pectin and hemicelluloses) were hydrolysed with $4 \mathrm{M}$ TFA at $120{ }^{\circ} \mathrm{C}$ for $2 \mathrm{~h}$. Insoluble DFs (i.e., pomace, pIDF fraction and cellulose) were submitted to sequential hydrolysis with varying concentrations of TFA (100, 85, 67, 46 and 30\% w/v) (Rowland \& Howley, 1989). Hydrolysed polysaccharides were then derivatised to volatile alditol acetates and analysed using an Agilent 7890A GC system (Santa Clara, CA, USA) coupled to an Agilent 5975C quadrupole MS. The samples were eluted from an HP-5 column $(30 \mathrm{~m} \times 0.25 \mathrm{~mm}, 0.25$ $\mu \mathrm{m}$ film) using helium as a carrier gas at a flow rate of $1 \mathrm{~mL} \min ^{-1}$ by applying the following temperature settings: start temperature $140{ }^{\circ} \mathrm{C}$, hold time $1 \mathrm{~min}$ and final column temperature $220{ }^{\circ} \mathrm{C}$ with $25^{\circ} \mathrm{C} \mathrm{min}{ }^{-1}$ gradient.

\subsection{Spectroscopic analysis}

\subsubsection{FT-IR spectroscopy}

FT-IR spectra were obtained between 500 and $4000 \mathrm{~cm}^{-1}$ for pomaces, soluble and insoluble fractions at a resolution of $4 \mathrm{~cm}^{-1}$ using 128 scans (Nicolet 380, Thermo Scientific, UK). Spectral smoothing was applied using instrument software (OMNIC 3.1). FT-IR spectra were also utilized for determination of degree of esterification of 
194 isolated pectins (Manrique \& Lajolo, 2002; Monsoor, Kalapathy, \& Proctor, 2001). DE

195 of pectins is proportional to the ratio:

196

$$
\mathrm{DE}=\frac{\text { area of esterified carboxyl groups }}{\text { area of total carboxyl groups }} 100
$$

197 The calibration curve was constructed using pectin standards with known DE values

198 and by correlating the DE values with the area ratio of esterified carboxylic groups over

199 the total carboxyl groups (esterified bands are centred around 1740 and non-esterified 200 around $\left.1630 \mathrm{~cm}^{-1}\right)$.

\subsection{2 ${ }^{13}$ C CPMAS NMR spectroscopy}

${ }^{13}$ C CPMAS NMR spectra were recorded on a Bruker AVANCE III 600 NMR

spectrometer with narrow bore magnet and 4-mm triple resonance probe. The

204 parameters and conditions used in ${ }^{13} \mathrm{C}$ CPMAS NMR experiments were: proton $90^{\circ}$ 205 pulse length $3 \mu$ s, field strength of the proton and spin locking fields during the contact period $83 \mathrm{kHz}$. The samples were packed into $4-\mathrm{mm}$ rotors and spun at $10 \mathrm{kHz}$.

207 Chemical shifts ( $\mathrm{ppm})$ scales were referenced to the upfield peak of adamantane $(29.5$ 208 ppm) run as an external standard. Proton decoupling was provided by a spinal-64 209 sequence and the proton power levels during the contact time and decoupling stage 210 could be varied independently to provide optimum signal to noise levels. The highest 211 intensity signal for all types of bonded carbons in these materials lies between a contact 212 time of 1 and $2 \mathrm{~ms}$. For all CPMAS experiments a value of $2 \mathrm{~ms}$ was used and recycle 213 delay was 2 s. Approximately 5000 data points were normally recorded. On data 214 processing this data set was zero-filled by at least a factor of 2. A Lorentzian line 215 broadening $(15 \mathrm{~Hz})$ was then applied. The data were Fourier-transformed and phased 216 with zero and first order corrections. Baseline fitting routines were applied to all 217 spectra. 
Two-dimensional (2D) NMR experiments were carried out on a Bruker 800

$220 \mathrm{MHz}$ Avance III spectrometer equipped with a QCI cryoprobe. For each sample the $22190^{\circ}$ pulse and transmitter frequency were calibrated. The number of scans collected in 222 each dimension for each experiment was determined by the sample concentration. The $2232 \mathrm{D}{ }^{13} \mathrm{C}[\mathrm{H}]$ HSQC spectra were acquired over a spectral width of $14 \mathrm{ppm}$ in the ${ }^{1} \mathrm{H}$ 224 dimension and $200 \mathrm{ppm}$ in the ${ }^{13} \mathrm{C}$ dimension. The transmitter frequency for carbon was 225 centred at $100 \mathrm{ppm}$ and between 16 and 64 scans were acquired, with 128 complex 226 points in $\mathrm{f1}$. Quadrature detection in the carbon channel was achieved using the States227 TPPI method. Data acquisition and processing were carried out using Topspin 3.5 228 software. For 2D datasets a shifted squared sine bell was used with the offset being 229 optimized to achieve the best balance between resolution and signal to noise ratio. All 230 data were zero-filled by at least a factor of 2. For heteronuclear dimensions linear 231 prediction was employed.

\subsection{Macromolecular characteristics of soluble DFs}

Weight-average molecular weight $\left(\mathrm{M}_{\mathrm{w}}\right)$ of pectins and hemicelluloses was determined using size exclusion chromatography coupled to multi-angle laser light scattering (SEC-MALLS) at $25^{\circ} \mathrm{C}$. Soluble fractions were stirred overnight in $0.1 \mathrm{M}$

$236 \mathrm{NaNO}_{3}$ solution (3-5 $\left.\mathrm{mg} \mathrm{mL}^{-1}\right)$ at room temperature. Solubilized fractions were injected 237 onto an SEC system (15 $\mu \mathrm{m}$ particle size, $25 \mathrm{~cm} \times 4 \mathrm{~mm}$, Agilent, Oxford, UK) that 238 consisted of a PL Aquagel guard column linked in series with PL Aquagel-OH 60, PL 239 Aquagel-OH 50 and PL Aquagel-OH 40. Fractions were eluted with $0.1 \mathrm{M} \mathrm{NaNO}$ 240 solution at a flow rate of $0.7 \mathrm{~mL} \mathrm{~min}^{-1}$. The eluent was then detected online firstly by a 241 DAWN EOS light scattering detector (Wyatt Technology, Santa Barbara, U.S.A.) and 242 finally by a rEX differential refractometer (Wyatt Technology, Santa Barbara, U.S.A.). 
243 The refractive index increment, $d n / d c$ was taken to be $0.146 \mathrm{~mL} \mathrm{~g}^{-1}$ for pectins and

$2440.060 \mathrm{~mL} \mathrm{~g}^{-1}$ for hemicelluloses (Chapman, Morris, Selvendran, \& O'Neill, 1987;

245 Morris, de al Torre, Ortega, Castile, Smith, \& Harding, 2008; Morris, Foster, \& 246 Harding, 2000; Xu, Leppanen, Eklund, Holmlund, Sjoholm, Sundberg, \& Willfor, 247 2010).

248 Intrinsic viscosity measurements were performed on pectins and 249 hemicelluloses. Samples were dispersed at $0.1-2.0 \mathrm{~g} \mathrm{dL}^{-1}$ in $0.1 \mathrm{M} \mathrm{NaCl}$ at $\mathrm{pH} 7.0 \mathrm{in}$ 250 Sorensen's phosphate buffer with $0.02 \mathrm{~g} \mathrm{dL}^{-1} \mathrm{NaN}_{3}$ and were stirred overnight. An 251 Ubbelohde capillary glass viscometer (PSL Rheotek OB. C 80705) and the Huggins 252 equation was used to estimate the intrinsic viscosities of the isolated fractions at $20 \pm$ $2530.1^{\circ} \mathrm{C}$.

\section{Results and discussion}

\subsection{Fractionation of DFs from blackcurrant pomace}

An isolation protocol (Figure 1) was designed to fractionate blackcurrant pomace into its constituent soluble and insoluble fractions. Fractionation commences with the isolation of acid-soluble pectin at $80{ }^{\circ} \mathrm{C}(\mathrm{pH} 2.0)$ followed by isolation of calcium-bound pectin with ammonium oxalate at $85^{\circ} \mathrm{C}(\mathrm{pH} 4.6)$. Hot acid treatment is Freitas, Iacomini, Mellinger-Silva, \& Cabral, 2016; Minjares-Fuentes, Femenia, Garau, 262 Meza-Velázquez, Simal, \& Rosselló, 2014b) usually resulting in high yields of high 263 molecular weight pectic polysaccharides (Alba \& Kontogiorgos, 2017). The calcium264 bound pectin fraction is insoluble in hot acid and requires the presence of a chelating 265 agent to remove calcium from intermolecular linkages and allow pectin to solubilise. The insoluble residue that remained after the extraction of pectic 267 polysaccharides represented the lignocellulosic biomass that was further fractionated 
into three major components, hemicellulose, cellulose and lignin (Figure 1). It has been

269 shown that strong alkali $(4 \mathrm{M} \mathrm{KOH})$ was more efficient in dissolving hemicelluloses

270 and resulted in higher extraction yields compared to $2 \mathrm{M} \mathrm{KOH}$ (Minjares-Fuentes,

271 Femenia, Garau, Candelas-Cadillo, Simal, \& Rosselló, 2016; Prozil, Costa, Evtuguin,

272 Lopes, \& Domingues, 2012). Other authors reported higher yields of hemicelluloses

273 isolated with $\mathrm{H}_{2} \mathrm{O}_{2}$ rather than with direct alkaline extraction due to high reactivity of

274 hydroxyl radicals that cleave ester links between lignin and hemicelluloses (Rabetafika,

275 Bchir, Blecker, Paquot, \& Wathelet, 2014). Therefore, to optimise the yield, isolation

276 of hemicelluloses was performed with $6 \% \mathrm{v} / \mathrm{v}_{2} \mathrm{O}_{2}$ under alkaline conditions. Note

277 that isolated pectins and hemicelluloses represent the fractions that can be used as

278 water-soluble dietary fibres based on their solubility in water after extraction from

279 pomace. Cellulose was separated from lignocellulose after hemicellulose extraction in

280 the form of a solid residue, whereas lignin was recovered by precipitation with acidified

281 water (Figure 1). Generally, yield, purity and macromolecular characteristics of

282 extracted cellulose and lignin vary depending on the isolation method, as described in

283 the following sections.

\subsection{Characterisation of blackcurrant pomace}

Proximate analysis of blackcurrant pomaces (Table 1) demonstrated

286 comparable amounts of both proteins and carbohydrates in the two pomace samples.

287 Higher protein content (17\% w/w) has been previously reported for blackcurrant and

288 bilberry pomaces (Hilz, Bakx, Schols, \& Voragen, 2005), however, analysis of grape

289 pomaces revealed a considerably lower amount of protein (2.7-3.8\% w/w) (González-

290 Centeno, Rosselló, Simal, Garau, López, \& Femenia, 2010). POMUK had a higher fat

291 content $(10.8 \%)$ than POMPOL (5.9\%), possibly due to higher seed content. These 
values were much higher than reported fat contents of grape pomaces $(0.3-1.0 \% \mathrm{w} / \mathrm{w})$

(Rabetafika, Bchir, Aguedo, Paquot, \& Blecker, 2013).

reported for blackcurrant, bilberry, chokeberry and raspberry pomaces or berries (56-

297 66\% w/w) (Jakobsdottir, Nilsson, Blanco, Sterner, \& Nyman, 2014; Jaroslawska,

298 Wroblewska, Juskiewicz, Brzuzan, \& Zdunczyk, 2016; Wawer, Wolniak, \&

299 Paradowska, 2006).

Table 1. Proximate analysis, fibre composition of blackcurrant pomaces and the yield 301 of constituent DF fractions.

\begin{tabular}{lll}
\hline & POMPOL & POMUK \\
\hline${\text { Protein }(\mathrm{N} \times 6.25)^{\mathrm{a}}}^{\mathrm{a}}$ & 11.1 & 13.3 \\
Ash $^{\mathrm{a}}$ & 3.3 & 2.8 \\
Moisture $^{\mathrm{a}}$ & 7.5 & 3.2 \\
Fat $^{\mathrm{a}}$ & 5.9 & 10.8 \\
Carbohydrate $^{\mathrm{a}}$ & 71.9 & 69.8 \\
\hline Total soluble DF $^{\mathrm{b}}$ & $30.0 \pm 1.5$ & $25.1 \pm 1.0$ \\
Acid-soluble pectin $^{\mathrm{c}}$ & $5.8 \pm 1.6$ & $2.9 \pm 1.0$ \\
Calcium-bound pectin $^{\mathrm{c}}$ & $9.8 \pm 0.1$ & $7.7 \pm 0.4$ \\
Alkali-soluble hemicelluloses $^{\mathrm{c}}$ & $14.4 \pm 3.0$ & $14.5 \pm 1.5$ \\
\hline Total insoluble DF $^{\mathrm{d}}$ & $46.9 \pm 4.6$ & $47.4 \pm 5.4$ \\
Cellulose $^{\mathrm{c}}$ & $17.2 \pm 1.8$ & $13.6 \pm 2.8$ \\
Alkali-soluble lignin $^{\mathrm{c}}$ & $0.4 \pm 0.2$ & $0.2 \pm 0.1$ \\
Ash & $3.7 \pm 0.6$ & $3.0 \pm 0.1$ \\
Klason lignin $^{\mathrm{c}}$ & $37.9 \pm 9.0$ & $35.7 \pm 11.3$ \\
Pure insoluble DF $^{\mathrm{c}}$ & $61.3 \pm 4.6$ & $61.9 \pm 5.4$ \\
\hline
\end{tabular}

302

303

304

305

306

307

308

309

310 312 lignin was the main cell wall component and also the major insoluble DF fraction in 313 both pomaces (Table 1) and was present in lower amounts compared to lignin values

${ }^{a}$ Values are expressed as \% wet basis.

${ }^{\mathrm{b}}$ Values were calculated by adding acid-soluble pectin, calcium-bound pectin and alkali-soluble hemicellulose. Values are expressed as $\% \mathrm{w} / \mathrm{w}(\mathrm{g} / 100 \mathrm{~g}$ of dry pomace). ${ }^{\mathrm{c}}$ Values are expressed as \% w/w (g/100 g of dry pomace).

${ }^{\mathrm{d}}$ Values were calculated by subtracting the alkali-soluble hemicellulose content (HEMUK, HEMPOL) from the amount of pure insoluble DF (pIDFUK, pIDFPOL). Values are expressed as \% w/w (g/100 g of dry pomace).

The amount of cellulose was 13.6 and $17.2 \%$ w/w for the two samples higher than a previously reported value of $12.0 \%$ w/w (Nawirska \& Kwaśniewska, 2005). Klason 
314 previously reported for blackcurrant or grape pomaces that ranged between 41.9 and 315 59.3\% w/w (Jakobsdottir, et al., 2014; Nawirska, et al., 2005; Valiente, Arrigoni, 316 Esteban, \& Amado, 1995). Generaly there is considerable variability in the composition 317 of the insoluble fibres depending on the source of extraction (e.g., berry or fruit co318 products) (Aguedo, Kohnen, Rabetafika, Vanden Bossche, Sterckx, Blecker, Beauve, 319 \& Paquot, 2012; Rabetafika, et al., 2013; Rabetafika, et al., 2014). Both samples had comparable contents of total soluble DF $(25-30 \% \mathrm{w} / \mathrm{w})$ in contrast to other studies that have reported considerably lower amounts $(5.4-7.8 \% \mathrm{w} / \mathrm{w})$ (Jakobsdottir, et al., 2014). The isolation protocol used in the current work includes not only acid-soluble pectins but also calcium-bound pectin and hemicelluloses, which 324 result in higher contents of total soluble fibre. The total pectin content (acid-soluble and $\mathrm{Ca}^{2+}$-bound pectin, Table 1) was greater in POMPOL than in POMUK but substantially higher than that previously reported from blackcurrant $(2.7 \% \mathrm{w} / \mathrm{w})$ (Nawirska, et al., 2005) or grape (2.0-6.2\% w/w) pomaces (González-Centeno, et al., 2010). The yields 328 of acid-soluble pectins (APUK $2.9 \% \mathrm{w} / \mathrm{w}$, APPOL $5.8 \% \mathrm{w} / \mathrm{w}$ ) in the current work were 329 lower than the yields reported for pectic HBSS fraction of blackcurrants $(12.1 \% \mathrm{w} / \mathrm{w})$ 330 or bilberries $(6.0 \% \mathrm{w} / \mathrm{w})$ (Hilz, et al., 2005). Those results suggest that part of the pectic 331 polysaccharide fraction has been removed during blackcurrant processing (e.g., 332 enzymic treatment during juice production) resulting in low contents of acid-soluble 333 pectin in both pomaces. Lower yields of pectic polysaccharides have been previously 334 reported from cherry pomace compared with cherries (Kosmala, Milala, 335 Kolodziejczyk, Markowski, Mieszczakowska, Ginies, \& Renard, 2009). On the other 336 hand, higher yields $(22.0 \% \mathrm{w} / \mathrm{w})$ of acid-soluble pectins were obtained from grape 337 pomace under comparable isolation conditions (Minjares-Fuentes, et al., 2014a). In 338 addition, the amounts of calcium-bound pectin were 7.7 and $9.8 \% \mathrm{w} / \mathrm{w}$ higher than 
reported for CHSS fractions isolated from unprocessed blackcurrant $(4.1 \% \mathrm{w} / \mathrm{w})$ and bilberries (4.0\% w/w) (Hilz, et al., 2005).

With regards to hemicelluloses, the extraction protocol resulted in isolation of comparable amounts of hemicellulosic polysaccharides from both samples (14.5 and $14.4 \% \mathrm{w} / \mathrm{w})$ lower than previously reported for blackcurrant pomace $(25.3 \% \mathrm{w} / \mathrm{w})$

344 (Nawirska, et al., 2005). The yield of hemicelluloses isolated from grape pomace using 345 alkaline extractions was in the range 5.4-8.0\% w/w and was considerably lower than 346 reported yields of those isolated from apple $(13.5 \% \mathrm{w} / \mathrm{w})$ or pear $(20.2,22.1 \% \mathrm{w} / \mathrm{w})$ 347 (Aguedo, et al., 2012; Minjares-Fuentes, et al., 2016; Rabetafika, et al., 2014). The physiological and technological properties of DF largely depend on the relative amounts of total soluble (SDF) and insoluble (IDF) fibre components, and the IDF/SDF ratio should range from 1.0 to 3.0 in order to yield optimal health benefits and functionality (Gomez, Ronda, Blanco, Caballero, \& Apesteguia, 2003). The IDF/SDF ratio was 1.9 for POMUK and 1.6 for POMPOL, indicating the suitability of these blackcurrant pomaces to be utilized as sources of DF.

\subsection{Chemical characterisation of pomaces and fractions}

Having established the overall composition of pomaces we proceeded with detailed carbohydrate analysis of both samples and their fractions. The two pomaces differed in the amount of total sugars, with higher values obtained for POMPOL (Table 2). These values are lower than total sugar contents reported for blackcurrant and 359 bilberry press cakes (34.0 and $36.0 \%$ w/w) (Hilz, et al., 2005) but comparable with 360 those from grape pomaces (15.6-32.5\% w/w) (González-Centeno, et al., 2010).

361 Blackcurrant pomaces were primarily composed of uronic acids and the major neutral 362 sugars were glucose and galactose, with other sugars present in lower proportions 363 (Table 2) in contrast to those previously reported (glucose $>$ mannose $>$ uronic acids) 
364 (Hilz, et al., 2005). Additionally, grape pomaces have shown variable sugar 365 composition (glucose $>$ uronic acids $>$ xylose or uronic acids $>$ glucose) exemplifying 366 the influence of botanical variety on sugar profile and molecular structure of pomace 367 polysaccharides (González-Centeno, et al., 2010).

368 APUK and APPOL fractions demonstrated comparable contents of uronic 369 acids, with major neutral sugars being galactose and arabinose while the third major 370 neutral sugar was glucose for APUK and rhamnose for APPOL (Table 2). CBPUK and 371 CBPPOL had similar uronic acid content but differed in neutral sugar composition with 372 galactose being the major neutral sugar in CBPUK (Table 2). Previous reports have 373 shown that isolation of pectic polysaccharides using various extraction solvents from 374 blackcurrant, cherry and cherry pomace yields samples containing mostly arabinose 375 and galactose (Hilz, et al., 2005; Kosmala, et al., 2009). The molecular structure of 376 isolated pectins was modelled using sugar molar ratios and calculated based on the 377 neutral sugar mol\% (Table 3). Ratios 1, 2 and HG/RG-I highlight the prevalence of 378 linear segments in the structure of APPOL, whereas other pectins exhibited higher 379 levels of branching (Denman \& Morris, 2015). In addition, ratio 3 demonstrates 380 moderate differences in the size of the branching of side chains. Previous studies have 381 also reported the isolation of homogalacturonan-rich pectins from blackcurrants and 382 bilberries (Hilz, et al., 2005). The same group also demonstrated the presence of large 383 amounts of rhamnogalacturonan-II (RG-II) in blackcurrant press cake, based on the 384 presence of several diagnostic sugars such as fucose and xylose (Hilz, Williams, Doco, 385 Schols, \& Voragen, 2006). Pectins isolated in the current work did not contain fucose 386 and had negligible amounts of xylose, suggesting that RG-II was not present. 
Table 2. Neutral sugar, uronic acid composition and Klason lignin of pomaces (POM) 389 and its soluble (AP, CBP, HEM) and insoluble fractions (pIDF, CEL) $(\% \mathrm{w} / \mathrm{w}$, wet 390 basis). Values in brackets are mol\% of each neutral sugar and uronic acids.

\begin{tabular}{|c|c|c|c|c|c|c|c|c|}
\hline & Rha & Ara & Xyl & Man & Gal & Glu & Uronic acids & $\begin{array}{l}\text { Klason } \\
\text { lignin }\end{array}$ \\
\hline \multicolumn{9}{|c|}{ POL } \\
\hline POM & $\begin{array}{l}0.05 \pm 0.14 \\
(0.3)\end{array}$ & $\begin{array}{l}0.11 \pm 0.01 \\
(0.6)\end{array}$ & $\begin{array}{l}0.13 \pm 0.01 \\
(0.7)\end{array}$ & $\begin{array}{l}0.11 \pm 0.05 \\
(0.5)\end{array}$ & $\begin{array}{l}0.45 \pm 0.02 \\
(2.1)\end{array}$ & $\begin{array}{l}4.67 \pm 0.03 \\
(21.4)\end{array}$ & $\begin{array}{l}17.68 \pm 4.72 \\
(74.5)\end{array}$ & $\begin{array}{l}37.91 \pm \\
9.06\end{array}$ \\
\hline pIDF & $\begin{array}{l}0.15 \pm 0.02 \\
(1.3)\end{array}$ & $\begin{array}{l}0.02 \pm 0.04 \\
(0.2)\end{array}$ & $\begin{array}{l}0.04 \pm 0.02 \\
(0.4)\end{array}$ & $\begin{array}{l}0.25 \pm 0.06 \\
(1.9)\end{array}$ & $\begin{array}{l}0.37 \pm 0.01 \\
(2.8)\end{array}$ & $\begin{array}{l}7.23 \pm 0.03 \\
(54.7)\end{array}$ & $\begin{array}{l}5.57 \pm 1.81 \\
(38.8)\end{array}$ & $\begin{array}{l}42.23 \pm \\
2.47\end{array}$ \\
\hline $\mathbf{A P}$ & $\begin{array}{l}1.22 \pm 0.08 \\
(2.4)\end{array}$ & $\begin{array}{l}4.29 \pm 0.25 \\
(9.4)\end{array}$ & $\begin{array}{l}0.32 \pm 0.02 \\
(0.7)\end{array}$ & - & $\begin{array}{l}2.95 \pm 0.29 \\
(5.3)\end{array}$ & $\begin{array}{l}1.05 \pm 0.10 \\
(1.9)\end{array}$ & $\begin{array}{l}48.60 \pm 4.88 \\
(80.2)\end{array}$ & - \\
\hline CBP & $\begin{array}{l}2.24 \pm 0.11 \\
(3.8)\end{array}$ & $\begin{array}{l}5.58 \pm 0.07 \\
(10.6)\end{array}$ & $\begin{array}{l}0.88 \pm 0.02 \\
(1.7)\end{array}$ & - & $\begin{array}{l}5.12 \pm 0.12 \\
(7.9)\end{array}$ & $\begin{array}{l}2.78 \pm 0.02 \\
(4.3)\end{array}$ & $\begin{array}{l}50.45 \pm 3.03 \\
(71.7)\end{array}$ & - \\
\hline HEM & $\begin{array}{l}1.07 \pm 0.03 \\
(2.7)\end{array}$ & $\begin{array}{l}5.34 \pm 0.27 \\
(14.8)\end{array}$ & $\begin{array}{l}9.32 \pm 0.19 \\
(25.9)\end{array}$ & $\begin{array}{l}1.37 \pm 0.14 \\
(3.1)\end{array}$ & $\begin{array}{l}6.68 \pm 0.29 \\
(15.1)\end{array}$ & $\begin{array}{l}6.20 \pm 0.06 \\
(14.0)\end{array}$ & $\begin{array}{l}11.71 \pm 0.75 \\
(24.4)\end{array}$ & - \\
\hline CEL & - & $\begin{array}{l}0.32 \pm 0.47 \\
(0.9)\end{array}$ & $\begin{array}{l}1.86 \pm 0.83 \\
(5.5)\end{array}$ & - & $\begin{array}{l}0.19 \pm 0.28 \\
(0.5)\end{array}$ & $\begin{array}{l}35.1 \pm 1.35 \\
(84.3)\end{array}$ & $\begin{array}{l}3.98 \pm 0.31 \\
(8.8)\end{array}$ & $\begin{array}{l}14.17 \pm \\
3.26\end{array}$ \\
\hline \multicolumn{9}{|c|}{ UK } \\
\hline POM & $\begin{array}{l}0.29 \pm 0.02 \\
(2.4)\end{array}$ & $\begin{array}{l}0.44 \pm 0.05 \\
(4.1)\end{array}$ & $\begin{array}{l}0.45 \pm 0.03 \\
(4.2)\end{array}$ & $\begin{array}{l}0.39 \pm 0.01 \\
(2.9)\end{array}$ & $\begin{array}{l}1.00 \pm 0.01 \\
(7.5)\end{array}$ & $\begin{array}{l}2.96 \pm 0.04 \\
(22.3)\end{array}$ & $\begin{array}{l}8.13 \pm 2.69 \\
(56.5)\end{array}$ & $\begin{array}{l}35.71 \pm \\
11.31\end{array}$ \\
\hline pIDF & $\begin{array}{l}0.05 \pm 0.02 \\
(0.5)\end{array}$ & $\begin{array}{l}0.06 \pm 0.01 \\
(0.6)\end{array}$ & $\begin{array}{l}0.16 \pm 0.04 \\
(1.6)\end{array}$ & $\begin{array}{l}0.38 \pm 0.03 \\
(3.1)\end{array}$ & $\begin{array}{l}0.47 \pm 0.03 \\
(3.8)\end{array}$ & $\begin{array}{l}6.52 \pm 0.06 \\
(53)\end{array}$ & $\begin{array}{l}5.01 \pm 0.33 \\
(37.5)\end{array}$ & $\begin{array}{l}44.39 \pm \\
3.83\end{array}$ \\
\hline $\mathbf{A P}$ & $\begin{array}{l}2.12 \pm 0.05 \\
(3.2)\end{array}$ & $\begin{array}{l}5.23 \pm 0.05 \\
(8.7)\end{array}$ & $\begin{array}{l}1.10 \pm 0.03 \\
(1.8)\end{array}$ & - & $\begin{array}{l}7.57 \pm 0.18 \\
(10.3)\end{array}$ & $\begin{array}{l}3.0 \pm 0.07 \\
(4.1)\end{array}$ & $\begin{array}{l}57.28 \pm 0.95 \\
(71.8)\end{array}$ & - \\
\hline CBP & $\begin{array}{l}1.79 \pm 0.43 \\
(3.4)\end{array}$ & $\begin{array}{l}3.86 \pm 0.76 \\
(8.1)\end{array}$ & $\begin{array}{l}1.45 \pm 0.30 \\
(3.0)\end{array}$ & - & $\begin{array}{l}5.13 \pm 0.13 \\
(8.8)\end{array}$ & $\begin{array}{l}3.81 \pm 0.25 \\
(6.5)\end{array}$ & $\begin{array}{l}44.53 \pm 10.45 \\
(70.1)\end{array}$ & - \\
\hline HEM & $\begin{array}{l}2.61 \pm 0.17 \\
(9.2)\end{array}$ & $\begin{array}{l}4.36 \pm 0.36 \\
(17.1)\end{array}$ & $\begin{array}{l}5.57 \pm 0.17 \\
(21.8)\end{array}$ & $\begin{array}{l}2.37 \pm 0.28 \\
(7.6)\end{array}$ & $\begin{array}{l}5.17 \pm 0.58 \\
(16.5)\end{array}$ & $\begin{array}{l}2.60 \pm 0.26 \\
(8.3)\end{array}$ & $\begin{array}{l}6.68 \pm 0.68 \\
(19.6)\end{array}$ & - \\
\hline CEL & - & $\begin{array}{l}0.67 \pm 0.25 \\
(1.3)\end{array}$ & $\begin{array}{l}10.1 \pm 0.76 \\
(20.4)\end{array}$ & - & $\begin{array}{l}7.27 \pm 0.85 \\
(11.9)\end{array}$ & $\begin{array}{l}39.1 \pm 2.6 \\
(64)\end{array}$ & $\begin{array}{l}1.60 \pm 0.66 \\
(2.4)\end{array}$ & $\begin{array}{l}18.13 \pm \\
4.51\end{array}$ \\
\hline
\end{tabular}

Table 3. Sugar molar ratios (\%) of pectins are shown as $\mathrm{R} 1=\mathrm{GalA} /(\mathrm{Rha}+\mathrm{Ara}+\mathrm{Gal})$; $395 \mathrm{R} 2=\mathrm{Rha} / \mathrm{GalA} ; \mathrm{R} 3=(\mathrm{Ara}+\mathrm{Gal}) / \mathrm{Rha} ; \mathrm{HG}(\mathrm{mol} \%)=\mathrm{GalA}(\mathrm{mol} \%)-\mathrm{Rha}(\mathrm{mol} \%)$; 396 RG-I $(\mathrm{mol} \%)=2 \times \operatorname{Rha}(\mathrm{mol} \%)+\operatorname{Ara}(\mathrm{mol} \%)+\mathrm{Gal}(\mathrm{mol} \%)$. GalA is expressed as 397 uronic acids shown in Table 2.

\begin{tabular}{lcccc}
\hline & APPOL & CBPPOL & APUK & CBPUK \\
\hline R1 $^{\mathrm{a}}$ & 4.70 & 3.22 & 3.23 & 3.45 \\
$\mathrm{R}^{\mathrm{a}}$ & 0.03 & 0.05 & 0.05 & 0.05 \\
\hline
\end{tabular}




\begin{tabular}{lcccc}
\hline R3 $^{\mathrm{b}}$ & 6.13 & 4.87 & 5.93 & 4.97 \\
HG & 77.80 & 67.90 & 68.60 & 66.70 \\
RG-I & 19.50 & 26.10 & 25.40 & 23.70 \\
HG/RG-I & 3.99 & 2.60 & 2.70 & 2.81 \\
DE $(\%)^{\mathrm{c}}$ & $38.2 \pm 1.1$ & $11.3 \pm 2.8$ & $33.2 \pm 2.1$ & $16.5 \pm 2.5$ \\
\hline
\end{tabular}

\section{${ }^{\mathrm{a}}$ Linearity}

${ }^{\mathrm{b}}$ Degree of branching of RG-I

${ }^{\mathrm{c} D}$ Degree of esterification

All pectin fractions isolated in this work were LM pectins and their degrees of esterification varied depending on the isolation conditions (Table 3). Both APUK (33 $\% \mathrm{DE}$ ) and APPOL (38\% DE) demonstrated comparable DE values that were higher than those obtained with chelating agent (CBPUK (16\% DE) and CBPPOL (11\% DE)). Chelating agents result in extraction of calcium-bound pectins that typically have a low degree of methylation (Ralet, Crépeau, Buchholt, \& Thibault, 2003). The isolation of LM pectins has been previously reported from grape (21-47\%), cherry pomace (10-19\%), blackcurrants $(49.2 \%)$, raspberry (45.8\%) and strawberry (46.0\%) (González-Centeno, et al., 2010; Kosmala, et al., 2009; Mierczynska, Cybulska, \& Zdunek, 2017; Minjares-Fuentes, et al., 2014a). In contrast, pectic polysaccharides isolated from blackcurrants and bilberries exhibited high degrees of methylation (Hilz, et al., 2005). Lower values of DE in the present work could be attributed to the extraction or processing conditions that result in losses of methyl groups of GalA. For instance, treatment of blackcurrant pomaces with various pectic enzymes (e.g., pectin methylesterases) prior to juice pressing results in lower number of methyl groups in blackcurrant pomaces compared to blackcurrants, leading to reduction of DE of isolated pectins. Losses of methyl groups have been also demonstrated for pectins isolated from sour cherry and sour cherry pomace (Kosmala, et al., 2009) or grapes and grape pomace (González-Centeno, et al., 2010).

Hemicelluloses were similar in terms of composition of neutral sugars and were mainly composed of xylose, arabinose and galactose indicating the presence of several 
424 hemicellulosic fractions (Table 2). Uronic acids were also identified in both fractions 425 and relatively higher amounts were detected in HEMPOL than in HEMUK. These 426 uronic acids could be a result of either oxidation of neutral sugars leading to the 427 formation of carboxylic acids in the presence of hydrogen peroxide or co-extracted 428 pectic polysaccharides. Hemicelluloses previously isolated from blackcurrant were 429 composed mainly of xylose, glucose and mannose and were identified as xyloglucans, 430 xylans and galactomannans (Hilz, de Jong, Kabel, Schols, \& Voragen, 2006) whereas 431 hemicelluloses isolated from grape pomace were mainly composed of xyloglucans, 432 mannans and xylans (Minjares-Fuentes, et al., 2016).

433 Glucose was the major sugar in CELUK and CELPOL, indicating that the 434 extraction protocol resulted in the efficient isolation of cellulosic materials. The 435 presence of galactose and xylose in both fractions suggests the co-extraction of pectic 436 and/or hemicellulosic polysaccharides with considerably lower contents of 437 contaminants in CELPOL fraction than in CELUK (Table 2). Previous work has also 438 demonstrated the presence of galactans in the cellulose fraction isolated from onion cell 439 wall (Foster, Ablett, McCann, \& Gidley, 1996). To confirm the structural and 440 compositional identity of isolates, detailed spectroscopic analysis (FTIR and NMR) 441 was carried out as described in the next sections.

$442 \quad 3.4$ FT-IR spectroscopy of DFs

443 Figure 2a illustrates typical FT-IR spectra of pomace, pure insoluble DF and the 444 cellulosic fraction. The prominent peaks at 1736 and $1615 \mathrm{~cm}^{-1}$ in the blackcurrant 445 pomaces have been assigned to either acetyl groups or $\mathrm{C}=\mathrm{O}$ bonds that are characteristic 446 for hemicelluloses, and methyl-esterified or free carboxyl groups that are specific for 447 pectin (Alemdar \& Sain, 2008). Those assignments were further corroborated by less 448 pronounced peaks in cellulose spectra due to the removal of the majority of the pectic 
449 and hemicellulosic polysaccharides during the extraction stages (Figure 2a). The peak 450 at $1523 \mathrm{~cm}^{-1}$ indicated the presence of lignin and was assigned to the aromatic skeletal 451 vibrations of lignin (Peng, Ren, Xu, Bian, Peng, \& Sun, 2009). Absorbances at 1367, 4521150 and $1040 \mathrm{~cm}^{-1}$ correspond to vibrations specific for cellulose or hemicellulose 453 (Sena Neto, Araujo, Souza, Mattoso, \& Marconcini, 2013).

454 Spectroscopic profiles of most bands of CELUK were comparable to those observed in 455 CELPOL, indicating similarities in the chemical structure of two samples. Absorbances 456 at $3336,2900,1641,1367,1319,1257,1150,1040$ and $889 \mathrm{~cm}^{-1}$ are typically 457 associated with native cellulose (Zhang, Dong, Ma, Zhang, Wang, \& Hu, 2015). 458 459 
a)

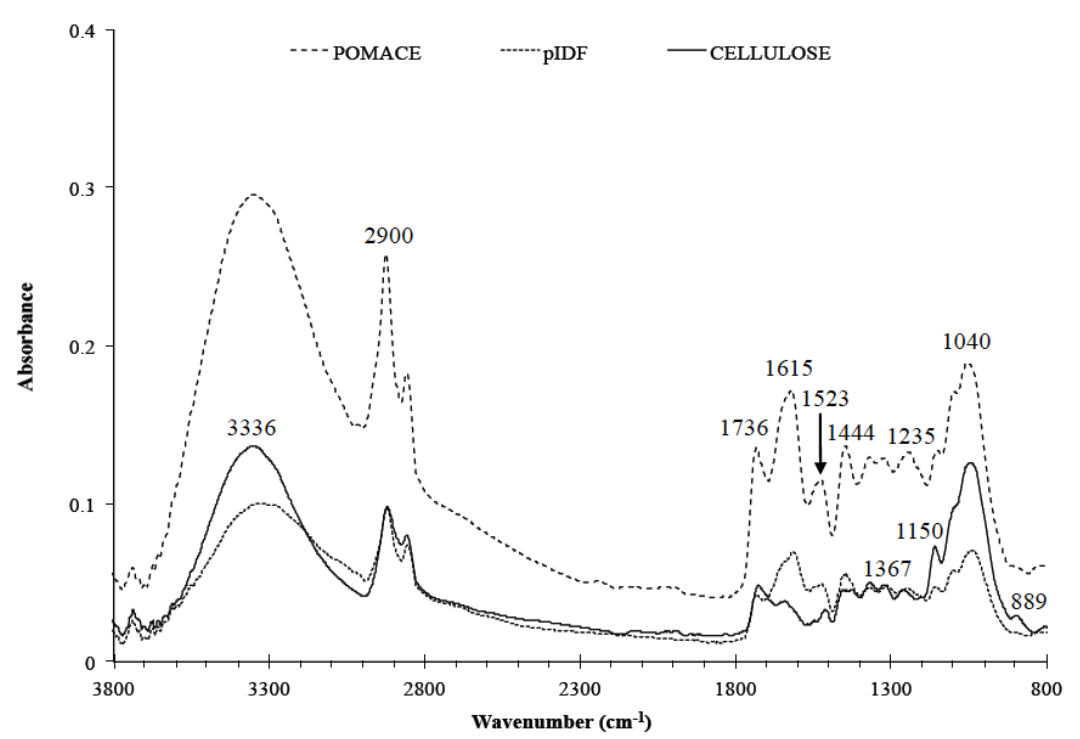

b)

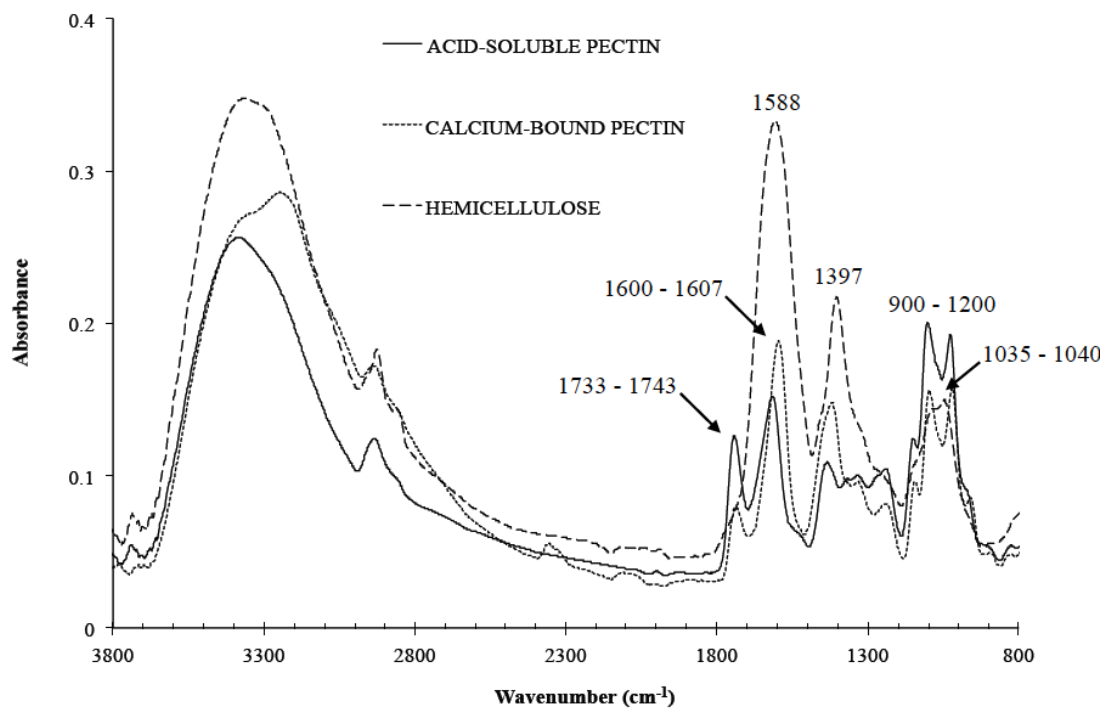

461 Figure 2. FT-IR spectra of POMUK and its fractions: (a) pomace, and insoluble 462 fractions (i.e., pure insoluble DF (pIDF) and cellulose), and (b) soluble fractions (i.e., 463 acid soluble pectin, calcium-bound pectin and hemicellulose). POMPOL and its 464 fractions showed similar spectra.

466 Absorbance at around $1257 \mathrm{~cm}^{-1}$ is typically associated with $\mathrm{O}-\mathrm{H}$ in plane bending of 467 cellulose. A broad peak at $1040 \mathrm{~cm}^{-1}$ originates from stretching of C-O-C bond 468 indicating the presence of pyranose rings. The minor peak at $889 \mathrm{~cm}^{-1}$ corresponds to 469 the deformation of glycosidic $\mathrm{C}_{1}-\mathrm{H}$ or ring vibrations that are specific for $\beta$-glycosidic 470 linkages between glucose monomers in cellulose (Zhang, et al., 2015). Both peaks are 
indicative of the cellulosic nature of fractions CELUK and CELPOL. A minor peak at

4721506 and $1423 \mathrm{~cm}^{-1}$ corresponded to the $\mathrm{C}=\mathrm{C}$ stretching and skeletal vibrations of 473 aromatic rings, and indicates the presence of negligible amounts of associated lignin in 474 the cellulosic fraction (Lan, Liu, \& Sun, 2011).

The spectra of all pectic fractions showed the presence of characteristic peaks 476 for pectins and also indicated moderate structural differences between isolated 477 polysaccharides (Figure 2b). The two major peaks for all four samples at around 3500 $478 \mathrm{~cm}^{-1}$ and $2500 \mathrm{~cm}^{-1}$ correspond to the $\mathrm{O}-\mathrm{H}$ stretching absorption due to inter- and intra479 molecular hydrogen bonding of uronic acids and the $\mathrm{C}-\mathrm{H}$ absorption of the rings, 480 respectively. Peaks at around $1733-1743 \mathrm{~cm}^{-1}$ were attributed to the ester carbonyl $481(\mathrm{C}=\mathrm{O})$ and those at $1600-1607 \mathrm{~cm}^{-1}$ were assigned to stretching of carboxylate anion of 482 GalA (Manrique, et al., 2002). The spectral region in the range of $900-1200 \mathrm{~cm}^{-1}$ 483 corresponds to skeletal C-O and C-C vibration bands of glycosidic bonds and pyranose 484 rings and reflects similarities in the neutral sugar composition of the isolated pectic 485 polysaccharides (Grassino, Halambek, Djaković, Rimac Brnčić, Dent, \& Grabarić, 486 2016) also supported by sugar composition analysis. The absorption bands at 1413$4871427 \mathrm{~cm}^{-1}$ suggest the presence of aliphatic or aromatic C-H groups possibly arising 488 from lignin. Minor peaks in the range 1320-1327 and $1232-1237 \mathrm{~cm}^{-1}$ were attributed 489 to $-\mathrm{OH}$ and $\mathrm{C}-\mathrm{O}$ bending vibrations (Bian, Peng, Peng, Xu, Sun, \& Kennedy, 2012) 490 that represent negligible amounts of co-extracted hemicellulosic compounds that have 491 also been shown in compositional analysis (Table 2). Prominent absorption bands of 492 hemicelluloses at 1035 and $1040 \mathrm{~cm}^{-1}$ were assigned to C-O, C-C, and the glycosidic 493 C-O-C stretching that are typically reported for arabinoxylans and xylans (Peng, et al., 494 2009; Sun, Wen, Ma, \& Sun, 2013). In addition, the band centred at $\sim 1397 \mathrm{~cm}^{-1}$ with 495 shoulders at around 1323 and $1249 \mathrm{~cm}^{-1}$ represents $\mathrm{C}-\mathrm{H}$ stretching, O-H or C-O bending 
vibrations in hemicelluloses (Bian, et al., 2012). The signal at $\sim 1588 \mathrm{~cm}^{-1}$ was assigned to carboxylates of uronic acids, the presence of which was also evidenced by compositional analysis of hemicellulosic fractions (Table 2). Other reports assign the band at $\sim 1592 \mathrm{~cm}^{-1}$ to symmetric stretching of $-\mathrm{COO}$ salts in $4-O$-methyl- $\alpha$-D500 glucuronic acid (Sun, et al., 2013). Generally, the spectral profiles of HEMUK and 501 HEMPOL were comparable, indicating structural similarities between fractions 502 obtained from two different blackcurrant pomaces. pure IDF fractions and the celluloses (Figure 3). In the up-field region of the spectra of 506 cellulose samples, the duplets between 61.4 and $70.6 \mathrm{ppm}$ were attributed to the $\mathrm{CH}_{2}$ 507 group of the C-6 atom. The next cluster of resonances, between 70.6 and $82.0 \mathrm{ppm}$, is assigned to the ring carbons (C-2, C-3 and C-5) other than those involved in the 509 glycosidic linkage (Atalla \& VanderHart, 1999; Kéri, Palcsu, Túri, Heim, Czébely, 510 Novák, \& Bányai, 2015; Wawer, et al., 2006). Resonances of carbons involved in the 511 glycosidic linkages appear at around 82.0 to $95.6 \mathrm{ppm}(\mathrm{C}-4)$ and the resonance at 107.6 $512 \mathrm{ppm}$ is of the anomeric carbon C-1. The appearance of C-6 and C-4 as duplets suggests 513 the presence of crystalline and disordered amorphous regions of cellulose (Wang, 514 Yang, Kubicki, \& Hong, 2016). Signals in the up-field region occurring at around 32.6 515 and 35.8 ppm were attributed to the aliphatic groups associated with extracted lipids. 516 Generally, the CP/MAS ${ }^{13} \mathrm{C}-\mathrm{NMR}$ spectra of cellulose showed that the isolated 517 fractions were free from hemicellulose and lignin due to the absence of any resonances 518 with typical chemical shifts corresponding to those compounds further confirming the 519 suitability of the fractionation protocol for isolation of pure cellulose. 


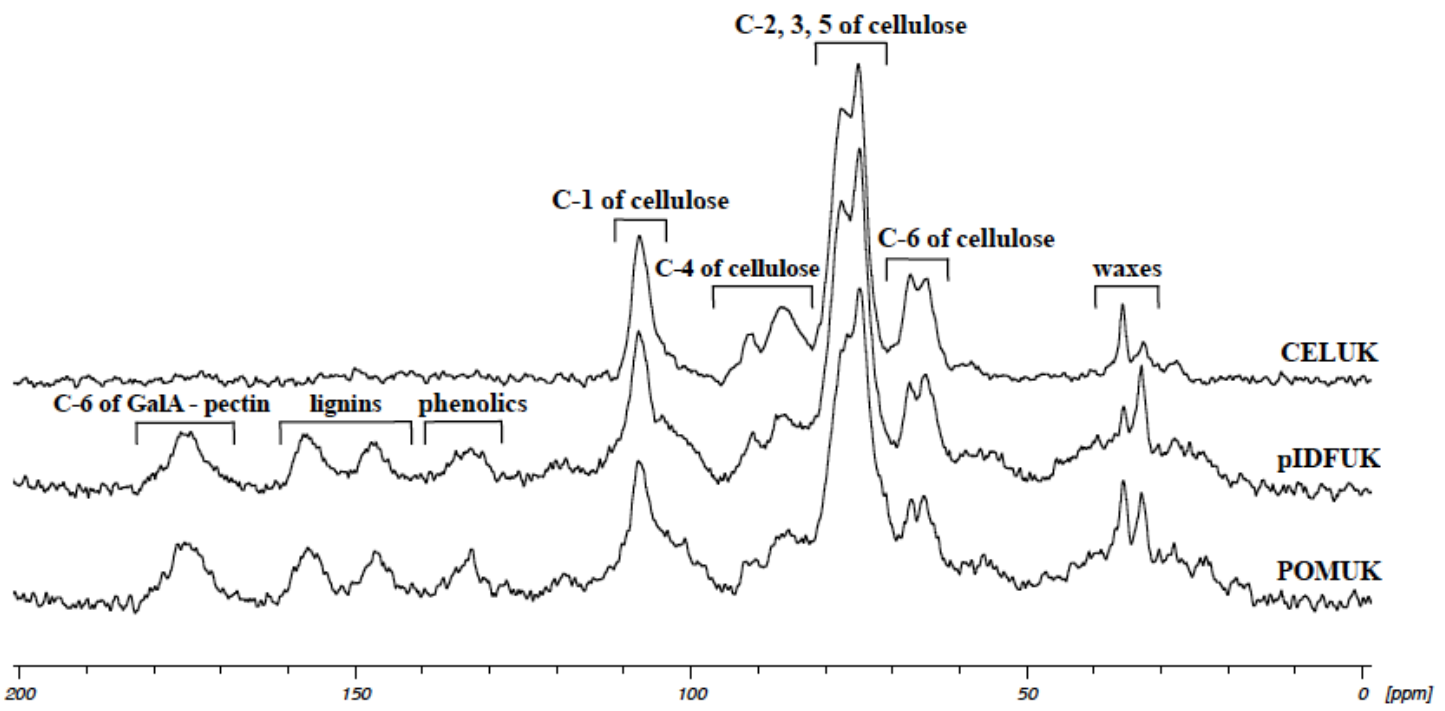

Figure 3. CP/MAS ${ }^{13} \mathrm{C}-\mathrm{NMR}$ spectra of CELUK, pIDFUK and POMUK. Spectra from pomace obtained from Poland showed similar traces. Chemical shifts were referenced to the upfield peak of adamantane $(29.5 \mathrm{ppm})$ run as an external standard.

Cellulose-like resonances were also identified in the pIDF and pomace spectra indicating the presence of cellulose in those fractions (Figure 3). A new signal was observed at $175.3 \mathrm{ppm}$ in the carbonyl region of spectra that corresponded to the C-6 of a methyl-esterified galacturonic acid. This shift is a characteristic signal for pectins and therefore highlights the presence of pectic compounds in pomace and pIDF. The presence of lignin in pIDF and pomace is evidenced by the signals occurring at 157.3 ppm and $147.5 \mathrm{ppm}$ that were identified as syringyl and quaiacyl (Wawer, et al., 2006). Resonances in the aromatic region (centred on $132.9 \mathrm{ppm}$ ) and also in the aliphatic region (31.3-38.0 ppm) of pomace and pIDF spectra (Figure 3) were attributed to the phenolic compounds and cutin that were previously reported for blackcurrant (Wawer, et al., 2006). Hemicellulose residues were not identified in the CP/MAS ${ }^{13} \mathrm{C}-\mathrm{NMR}$ spectra of pomace or pIDF due to the possible signal overlaps with intense resonances from cellulose and pectins. 

signals typical for pectic compounds (Figure 4a). The cluster of ${ }^{1} \mathrm{H} /{ }^{13} \mathrm{C}$ cross-peaks in 540 the range of 3.6-4.6/69.0-84.1 ppm was assigned to protons (H-2, 3, 4, 5) and carbons $541(\mathrm{C}-2,3,4,5)$ of galacturonic acid rings. Additional resonances of galacturonic acid 542 rings were identified at around 4.90-5.5/65.0-84.1 ppm due to the signals shift caused 543 by acetylation of the attached - $\mathrm{OH}$. The group of resonances at $\delta_{\mathrm{H}} / \delta_{\mathrm{C}} 4.8-5.5 / 95.9-110.6$ 544 ppm shows the presence of a number of polysaccharide anomeric protons (H-1) and 545 carbons $(\mathrm{C}-1)$. The $-\mathrm{OCH}_{3}$ of galacturonic acid was identified at $\delta_{\mathrm{H}} / \delta_{\mathrm{C}} 3.97 / 53.1 \mathrm{ppm}$, 546 whereas non-bonded C-6 of neutral sugars appeared at $\delta_{\mathrm{H}} / \delta_{\mathrm{C}} 3.6-4.4 / 59.8-69.0 \mathrm{ppm}$. In 547 the up-field region of the HSQC spectra, cross-peaks at $\delta_{\mathrm{H}} / \delta_{\mathrm{C}} 1.46,1.52 / 16.6 \mathrm{ppm}$ were 548 assigned as belonging to the $-\mathrm{CH}_{3}$ of rhamnose and signals at $\delta_{\mathrm{H}} / \delta_{\mathrm{C}} 2.30,2.4 / 20.1 \mathrm{ppm}$ 549 were identified as the $\mathrm{COCH}_{3}$ of acetyl groups.

Signals of the hemicellulosic fractions $\left(\delta_{\mathrm{H}} / \delta_{\mathrm{C}} 6.7-7.4 / 114.3-131.4\right)$ in the 551 aromatic region indicate the presence of moderate amounts of lignin in the isolated 552 samples that can be attributed to guaiacyl, syringyl or $p$-hydroxycinnamic acid units 553 that typically occur at $\delta_{\mathrm{H}} / \delta_{\mathrm{C}} 6.7-7.0 / 103-119,6.7 / 103$ and $7.3 / 130 \mathrm{ppm}$ (Figure $4 \mathrm{~b}$ ) 554 (Foston, Samuel, \& Ragauskas, 2012). Well-resolved resonances were observed in the 555 anomeric region $\left(\delta_{\mathrm{H}} / \delta_{\mathrm{C}} 4.4-5.4 / 96.6-110.9 \mathrm{ppm}\right)$ that can be tentatively assigned to $\mathrm{H}-$ 5561 and $\mathrm{C}-1$ of arabinose and galactose with typical $\delta_{\mathrm{H}} / \delta_{\mathrm{C}}$ in the range of 5.1-5.4/108.5$557 \quad 110.4$ and 4.4/102.6 ppm (Das, Mondal, Roy, Maiti, Bhunia, Maiti, \& Islam, 2009; 558 Fischer, Yu, Gray, Ralph, Anderson, \& Marlett, 2004). In the carbohydrate ring region, 559 complex signals were observed and some of the cross-peaks were attributed to 560 arabinose (3.8/76.2 ppm), xylose (3.6/74.0 ppm), glucose (3.3/72.8 ppm) and mannose 561 (4.6, 4.7/71.3 ppm) units by comparing chemical shifts with those published in 

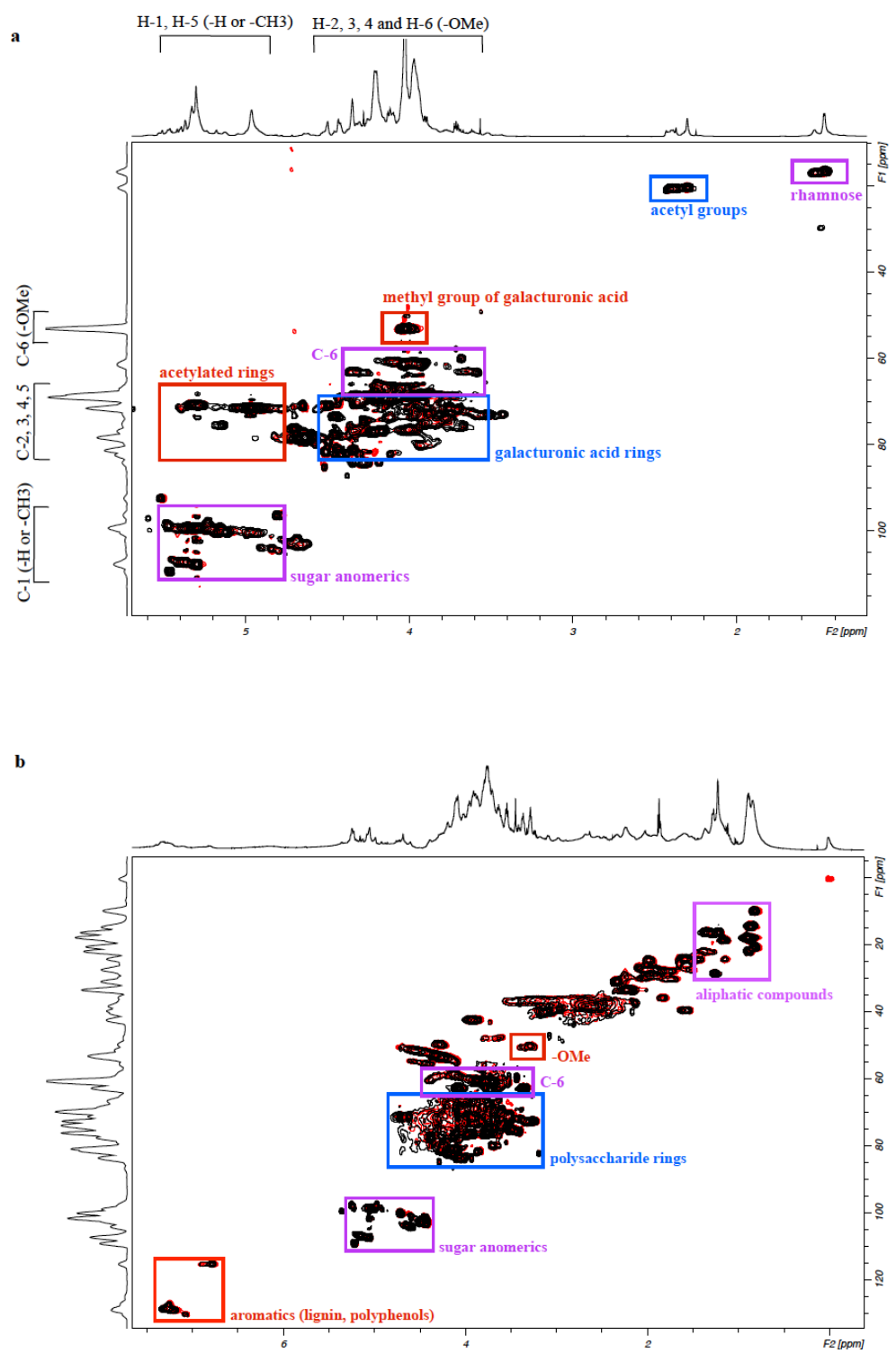

565 Figure 4. (a) HSQC spectra of CBPUK (black) and CBPPOL (red) recorded in $\mathrm{D}_{2} \mathrm{O}$ at $50{ }^{\circ} \mathrm{C}$. Similar spectra and correlation of proton/carbon signals were observed for APUK and APPOL (data not shown), (b) HSQC spectra of HEMUK (black) and HEMPOL (red) recorded in $\mathrm{D}_{2} \mathrm{O}$ at $50{ }^{\circ} \mathrm{C}$. In the carbohydrate ring region $\left(\delta_{\mathrm{H}} / \delta_{\mathrm{C}} 3.1-\right.$ 4.8/65.0-85.7 ppm), signals originated from arabinose, xylose, glucose and mannose.

571 with $O$-Me bonded to carboxyl groups. Three cross-peaks at $\delta_{\mathrm{H}} / \delta_{\mathrm{C}} 3.5-4.3 / 41.3-52.3$

$572 \mathrm{ppm}$, all originated from $-\mathrm{OCH}_{3}$, highlight the presence of at least three different sugar 573 units with $O$-Me bonded to carboxyl groups. The cluster of resonances at $\delta_{\mathrm{H}} / \delta_{\mathrm{C}} 0.8$ - 
$574 \quad 1.5 / 8.6-30.6 \mathrm{ppm}$ indicates the presence of aliphatic compounds, such as cutin that has 575 been previously reported at 30.0-32.5 ppm (Wawer, et al., 2006). Combining 576 information from three different analytical techniques (sugar analysis, FTIR and NMR) 577 it becomes evident that the present protocol results in a rather heterogeneous 578 hemicellulosic fraction, as it was not possible to identify a particular type of 579 hemicellulose (e.g., xyloglucans, mannans or xylans). As the solution behaviour of the 580 soluble fibres affect their functional and physiological properties, it is imperative to 581 understand their macromolecular characteristics; these are described in the next section.

\subsection{Macromolecular characteristics of soluble DFs}

The weight-average molecular weights $\left(\mathrm{M}_{\mathrm{w}}\right)$ of blackcurrant pectins ranged 584 from $29.4 \times 10^{3} \mathrm{~g} \mathrm{~mol}^{-1}$ to $109.6 \times 10^{3} \mathrm{~g} \mathrm{~mol}^{-1}$ with the lowest values recorded for 585 calcium-bound pectins (Table 4). Previous investigations have reported comparable $\mathrm{M}_{\mathrm{w}}$ 586 for HBSS and CHSS pectin fractions isolated from blackcurrant and bilberry pomaces 587 (Hilz, et al., 2005). In contrast to the current results, pectins isolated with chelating 588 agents from citrus fruits, mango and banana had considerably higher $\mathrm{M}_{\mathrm{w}}$ and intrinsic 589 viscosities than those obtained with acid extractions (Kaya, Sousa, Crepeau, Sorensen, 590 \& Ralet, 2014; Koubala, Kansci, Mbome, Crépeau, Thibault, \& Ralet, 2008). 591 Variations in $\mathrm{M}_{\mathrm{w}}$ between different pectin fractions could be attributed to the isolation 592 of smaller polymers since some of the pectic polysaccharides may have been already 593 removed from pomace during blackcurrant juice manufacturing or due to the partial acid hydrolysis of polysaccharides that occurs at elevated temperatures.

The highest $\mathrm{M}_{\mathrm{w}}$ was recorded for APUK $\left(109.6 \times 10^{3} \mathrm{~g} \mathrm{~mol}^{-1}\right)$ and pectins with

596 comparable $\mathrm{M}_{\mathrm{w}}\left(109.6-132.3 \times 10^{3} \mathrm{~g} \mathrm{~mol}^{-1}\right)$ have been previously extracted from grape 597 pomace under similar isolation conditions (Minjares-Fuentes, et al., 2014a). Molecular 598 weight of APUK was higher than the rest of pectin samples, despite the fact that its $[\eta]$ 
values were lower, thus indicating differences in chain flexibility. This is in agreement

600 with the structural analysis (Table 3) that highlights the role of branching particularly

601 for APUK. Therefore higher flexibility, as demonstrated by APUK fractions, is due to

602 the presence of RG-I regions resulting in formation of compact structures with lower

603 hydrodynamic volume. It should be noted that the intrinsic viscosity of isolated pectin

604 fractions was considerably lower than previously reported for citrus (e.g., orange,

605 lemon, lime and grapefruit, 4.0-8.0 $\left.\mathrm{dL} \mathrm{g}^{-1}\right)$, sugar beet (2.1-4.1 $\left.\mathrm{dL} \mathrm{g}^{-1}\right)$, okra (2.9-5.1

$606 \mathrm{dL} \mathrm{g}^{-1}$ ) or passionfruit pectins (4.7-5.8 $\mathrm{dL} \mathrm{g}^{-1}$ ) (Kaya, et al., 2014; Kpodo, Agbenorhevi,

607 Alba, Bingham, Oduro, Morris, \& Kontogiorgos, 2017; Levigne, Ralet, \& Thibault,

608 2002; Yapo \& Koffi, 2008). The weight-average molecular weight $\left(\mathrm{M}_{\mathrm{w}}\right)$ of

609 hemicellulosic polysaccharides were $1059 \times 10^{3} \mathrm{~g} \mathrm{~mol}^{-1}$ and $1167 \times 10^{3} \mathrm{~g} \mathrm{~mol}^{-1}$ while

$610[\eta]$ was $0.52-0.56 \mathrm{dL} \mathrm{g}^{-1}$ for HEMUK and HEMPOL, respectively (Table 4).

611 Hemicelluloses were of particularly high $\mathrm{M}_{\mathrm{w}}$, similar to those extracted from pear

612 pomace also using hydrogen peroxide (Rabetafika, et al., 2014). This has been

613 attributed to the ability of hydrogen peroxide to favour the isolation of high molecular

614 weight polysaccharides or to the strong tendency of hemicelluloses to form aggregates

615 in aqueous solutions that could contribute to overestimation of $\mathrm{M}_{\mathrm{w}}$.

616 Table 4. Macromolecular characteristics of soluble DFs.

\begin{tabular}{lcccccc}
\hline & APUK & CBPUK & APPOL & CBPPOL & HEMUK & HEMPOL \\
\hline $\begin{array}{l}\mathrm{M}_{\mathrm{w}} \times 10^{3}, \\
\mathrm{~g} \mathrm{~mol}^{-1}\end{array}$ & 109.6 & 31.3 & 45.5 & 29.4 & 1059 & 1167 \\
$\mathrm{M}_{\mathrm{w}} / \mathrm{M}_{\mathrm{n}}$ & 3.0 & 3.0 & 2.9 & 2.8 & 10.2 & 10.4 \\
& & & & & & \\
{$[\eta], \mathrm{dL} \mathrm{g}^{-}$} & 0.38 & 0.58 & 0.66 & 0.57 & 0.52 & 0.56 \\
\hline
\end{tabular}

617 4. Conclusions

618 Molecular characterization and spectroscopy revealed that fractions isolated

619 from blackcurrant pomaces corresponded to pectin, hemicellulose and cellulose. 
620 Isolated pectin samples contained $48-57 \% \mathrm{w} / \mathrm{w}$ and $45-50 \% \mathrm{w} / \mathrm{w}$ of galacturonic acid

621 for acid-soluble and calcium-bound pectins, respectively. Chemical analysis of acid-

622 soluble and calcium-bound pectins revealed small amounts of neutral sugars, primarily

623 galactose and arabinose, indicating the predominantly branched nature of the

624 biopolymer backbone, except for acid-soluble pectin isolated from POMPOL that was

625 more linear. Isolated pectins had low degree of esterification with the lowest values

626 obtained for calcium-bound pectin. Weight average molecular weight of pectin ranged

627 between about $30-110 \times 10^{3} \mathrm{~g} \mathrm{~mol}^{-1}$. Hemicelluloses were mainly composed of xylose

628 and galactose with particularly high molecular weight. The IDF/SDF ratio for POMUK

629 was 1.9 and for POMPOL was 1.6, indicating the suitability of blackcurrant pomaces

630 to be utilized as a source of DF in food formulations. Overall, the current work showed

631 that blackcurrant processing waste streams are a potential source of both soluble and

632 insoluble DFs, confirming our initial hypothesis that this raw material could be

633 successfully fractionated into fibre streams with distinct compositions and properties

634 and hence end-uses. Blackcurrant pomace could be used to obtain new functional

635 ingredients or to enhance the fibre content of foods, with minor differences observed 636 between the two places of origin (UK or Poland) and processing conditions.

\section{4. Acknowledgements}

638 The research project was approved during the $2^{\text {nd }}$ SUSFOOD ERA-Net call 639 (www.susfood-era.net). The authors wish to acknowledge the financial support of 640 DEFRA, UK (Grant \#FO0319). We thank H.E.L. Williams for help with the processing 641 of NMR spectroscopic data.

\section{5. References}

643 Aguedo, M., Kohnen, S., Rabetafika, N., Vanden Bossche, S., Sterckx, J., Blecker, C., 644 Beauve, C., \& Paquot, M. (2012). Composition of by-products from cooked 
fruit processing and potential use in food products. Journal of Food Composition and Analysis, 27, 61-69.

Alba, K., \& Kontogiorgos, V. (2017). Pectin at the oil-water interface: Relationship of molecular composition and structure to functionality. Food Hydrocolloids, 68, 211-218.

Alemdar, A., \& Sain, M. (2008). Isolation and characterization of nanofibers from agricultural residues: wheat straw and soy hulls. Bioresour Technol, 99, 16641671.

Atalla, R. H., \& VanderHart, D. L. (1999). The role of solid state 13C NMR spectroscopy in studies of the nature of native celluloses. Solid State Nuclear Magnetic Resonance, 15 1-19.

Beres, C., Simas-Tosin, F. F., Cabezudo, I., Freitas, S. P., Iacomini, M., MellingerSilva, C., \& Cabral, L. M. C. (2016). Antioxidant dietary fibre recovery from Brazilian Pinot noir grape pomace. Food Chemistry, 201, 145-152.

Bian, J., Peng, F., Peng, X.-P., Xu, F., Sun, R.-C., \& Kennedy, J. F. (2012). Isolation of hemicelluloses from sugarcane bagasse at different temperatures: Structure and properties. Carbohydrate Polymers, 88, 638-645.

Chapman, H. D., Morris, V. J., Selvendran, R. R., \& O'Neill, M. A. (1987). Static and dynamic light-scattering studies of pectic polysaccharides from the middle lamellae and primary cell walls of cider apples. Carbohydrate Research, 165, 53-68.

Das, D., Mondal, S., Roy, S. K., Maiti, D., Bhunia, B., Maiti, T. K., \& Islam, S. S. (2009). Isolation and characterization of a heteropolysaccharide from the corm of Amorphophallus campanulatus. Carbohydrate Research, 344, 2581-2585.

Denman, L. J., \& Morris, G. A. (2015). An experimental design approach to the chemical characterisation of pectin polysaccharides extracted from Cucumis melo Inodorus. Carbohydr Polym, 117, 364-369.

DeVries, J. W., Camire, M. E., Cho, S., Craig, S., Gordon, D., Jones, J. M., Li, B., Lineback, D., Prosky, L., \& Tungland, B. C. (2001). The definition of dietary fiber. Cereal Foods World, 46, 112-129.

Englyst, H. N., \& Cummings, J. H. (1988). Improved method for measurement of dietary fiber as non-starch polysaccharides in plant foods. Journal of the Association of Official Analytical Chemists, 71, 808-814.

Femenia, A. (2007). High-value co-products from plant foods: cosmetics and pharmaceuticals. . In K. Waldron (Ed.), Handbook of waste mangement and coproduct recovery in food processing, (Vol. 1, pp. 470-501). Cambridge: Woodhead Publishing Limited.

Filisetti-Cozzi, T. M. C. C., \& Carpita, N. C. (1991). Measurement of uronic acids without interference from neutral sugars. Analytical Biochemistry, 197, 157162. 
Fischer, M. H., Yu, N., Gray, G. R., Ralph, J., Anderson, L., \& Marlett, J. A. (2004). The gel-forming polysaccharide of psyllium husk (Plantago ovata Forsk). Carbohydrate Research, 339, 2009-2017.

Foster, T. J., Ablett, S., McCann, M. C., \& Gidley, M. J. (1996). Mobility-resolved 13C-NMR spectroscopy of primary plant cell walls. Biopolymers, 39, 51-66.

Foston, M., Samuel, R., \& Ragauskas, A. J. (2012). 13C cell wall enrichment and ionic liquid NMR analysis: progress towards a high-throughput detailed chemical analysis of the whole plant cell wall. Analyst, 137, 3904-3909.

Gomez, M., Ronda, F., Blanco, C. A., Caballero, P. A., \& Apesteguia, A. (2003). Effect of dietary fibre on dough rheology and bread quality. European Food Research and Technology, 216, 51-56.

González-Centeno, M. R., Rosselló, C., Simal, S., Garau, M. C., López, F., \& Femenia, A. (2010). Physico-chemical properties of cell wall materials obtained from ten grape varieties and their byproducts: grape pomaces and stems. LWT - Food Science and Technology, 43, 1580-1586.

Grassino, A. N., Halambek, J., Djaković, S., Rimac Brnčić, S., Dent, M., \& Grabarić, Z. (2016). Utilization of tomato peel waste from canning factory as a potential source for pectin production and application as tin corrosion inhibitor. Food Hydrocolloids, 52, 265-274.

Hilz, H., Bakx, E. J., Schols, H. A., \& Voragen, A. G. J. (2005). Cell wall polysaccharides in black currants and bilberries - characterisation in berries, juice, and press cake. Carbohydrate Polymers, 59, 477-488.

Hilz, H., de Jong, L. E., Kabel, M. A., Schols, H. A., \& Voragen, A. G. (2006). A comparison of liquid chromatography, capillary electrophoresis, and mass spectrometry methods to determine xyloglucan structures in black currants. $J$ Chromatogr A, 1133, 275-286.

Hilz, H., Williams, P., Doco, T., Schols, H. A., \& Voragen, A. G. J. (2006). The pectic polysaccharide rhamnogalacturonan II is present as a dimer in pectic populations of bilberries and black currants in muro and in juice. Carbohydrate Polymers, 65, 521-528.

Jakobsdottir, G., Nilsson, U., Blanco, N., Sterner, O., \& Nyman, M. (2014). Effects of Soluble and Insoluble Fractions from Bilberries, Black Currants, and Raspberries on Short-Chain Fatty Acid Formation, Anthocyanin Excretion, and Cholesterol in Rats. Journal of Agricultural and Food Chemistry, 62, 43594368.

Jaroslawska, J., Wroblewska, M., Juskiewicz, J., Brzuzan, L., \& Zdunczyk, Z. (2016). Protective effects of polyphenol-rich blackcurrant preparation on biochemical and metabolic biomarkers of rats fed a diet high in fructose. J Anim Physiol Anim Nutr (Berl), 100, 136-145. 
Jenkins, D. J. A., Kendall, C. W. C., \& Ransom, T. P. P. (1998). Dietary fiber, the evolution of the human diet and coronary heart disease. Nutrition Research, 18, 633-652.

Kang, J., Cui, S. W., Phillips, G. O., Chen, J., Guo, Q., \& Wang, Q. (2011). New studies on gum ghatti (Anogeissus latifolia) part II. Structure characterization of an arabinogalactan from the gum by 1D, 2D NMR spectroscopy and methylation analysis. Food Hydrocolloids, 25, 1991-1998.

Kaya, M., Sousa, A. G., Crepeau, M. J., Sorensen, S. O., \& Ralet, M. C. (2014). Characterization of citrus pectin samples extracted under different conditions: influence of acid type and pH of extraction. Annals of Botany, 114, 1319-1326.

Kendall, C. W. C., Esfahani, A., \& Jenkins, D. J. A. (2010). The link between dietary fibre and human health. Food Hydrocolloids, 24, 42-48.

Kéri, M., Palcsu, L., Túri, M., Heim, E., Czébely, A., Novák, L., \& Bányai, I. (2015). 13C NMR analysis of cellulose samples from different preparation methods. Cellulose, 22, 2211-2220.

Kosmala, M., Milala, J., Kolodziejczyk, K., Markowski, J., Mieszczakowska, M., Ginies, C., \& Renard, C. M. (2009). Characterization of cell wall polysaccharides of cherry (Prunus cerasus var. Schattenmorelle) fruit and pomace. Plant Foods Hum Nutr, 64, 279-285.

Koubala, B. B., Kansci, G., Mbome, L. I., Crépeau, M. J., Thibault, J. F., \& Ralet, M. C. (2008). Effect of extraction conditions on some physicochemical characteristics of pectins from "Améliorée" and "Mango" mango peels. Food Hydrocolloids, 22, 1345-1351.

Kpodo, F. M., Agbenorhevi, J. K., Alba, K., Bingham, R. J., Oduro, I. N., Morris, G. A., \& Kontogiorgos, V. (2017). Pectin isolation and characterization from six okra genotypes. Food Hydrocolloids, 72, 323-330.

Lan, W., Liu, C.-F., \& Sun, R.-C. (2011). Fractionation of Bagasse into Cellulose, Hemicelluloses, and Lignin with Ionic Liquid Treatment Followed by Alkaline Extraction. Journal of Agricultural and Food Chemistry, 59, 8691-8701.

Larrauri, J. A. (1999). New approaches in the preparation of high dietary fibre powders from fruit by-products. Trends in Food Science and Technology, 10, 3-8.

Levigne, S., Ralet, M.-C., \& Thibault, J.-F. (2002). Characterization of pectins extracted from fresh sugar beet under different conditions using an experimental design. Carbohydrate Polymers, 49, 145-153.

Makris, D. P., Boskou, G., \& Andrikopoulos, N. K. (2007). Polyphenolic content and in vitro antioxidant characteristics of wine industry and other agri-food solid waste extracts. Journal of Food Composition and Analysis, 20, 125-132.

Mann, J. I., \& Cummings, J. H. (2009). Possible implications for health of the different definitions of dietary fibre. Nutr Metab Cardiovasc Dis, 19, 226-229. 
Manrique, G. D., \& Lajolo, F. M. (2002). FT-IR spectroscopy as a tool for measuring degree of methyl esterification in pectins isolated from ripening papaya fruit. Postharvest Biology and Technology, 25, 99-107.

Mierczynska, J., Cybulska, J., \& Zdunek, A. (2017). Rheological and chemical properties of pectin enriched fractions from different sources extracted with citric acid. Carbohydr Polym, 156, 443-451.

Minjares-Fuentes, R., Femenia, A., Garau, M. C., Candelas-Cadillo, M. G., Simal, S., \& Rosselló, C. (2016). Ultrasound-assisted extraction of hemicelluloses from grape pomace using response surface methodology. Carbohydrate Polymers, $138,180-191$.

Minjares-Fuentes, R., Femenia, A., Garau, M. C., Meza-Velazquez, J. A., Simal, S., \& Rossello, C. (2014a). Ultrasound-assisted extraction of pectins from grape pomace using citric acid: a response surface methodology approach. Carbohydr Polym, 106, 179-189.

Minjares-Fuentes, R., Femenia, A., Garau, M. C., Meza-Velázquez, J. A., Simal, S., \& Rosselló, C. (2014b). Ultrasound-assisted extraction of pectins from grape pomace using citric acid: A response surface methodology approach. Carbohydrate Polymers, 106, 179-189.

Monsoor, M. A., Kalapathy, U., \& Proctor, A. (2001). Improved method for determination of pectin degree of esterification by diffuse reflectance Fourier transform infrared spectroscopy. Journal of Agricultural and Food Chemistry, 49, 2756-2760.

Morris, G. A., de al Torre, J. G., Ortega, A., Castile, J., Smith, A., \& Harding, S. E. (2008). Molecular flexibility of citrus pectins by combined sedimentation and viscosity analysis. Food Hydrocolloids, 22, 1435-1442.

Morris, G. A., Foster, T. J., \& Harding, S. E. (2000). The effect of the degree of esterification on the hydrodynamic properties of citrus pectin. Food Hydrocolloids, 14, 227-235.

Nawirska, A., \& Kwaśniewska, M. (2005). Dietary fibre fractions from fruit and vegetable processing waste. Food Chemistry, 91, 221-225.

Pelucchi, C., Talamini, R., Galeone, C., Negri, E., Franceschi, S., Dal Maso, L., Montella, M., Conti, E., \& La Vecchia, C. (2004). Fibre intake and prostate cancer risk. International Journal of Cancer, 109, 278-280.

Peng, F., Ren, J. L., Xu, F., Bian, J., Peng, P., \& Sun, R. C. (2009). Comparative study of hemicelluloses obtained by graded ethanol precipitation from sugarcane bagasse. J Agric Food Chem, 57, 6305-6317.

Prozil, S. O., Costa, E. V., Evtuguin, D. V., Lopes, L. P., \& Domingues, M. R. (2012). Structural characterization of polysaccharides isolated from grape stalks of Vitis vinifera L. Carbohydr Res, 356, 252-259. 
Rabetafika, H. N., Bchir, B., Aguedo, M., Paquot, M., \& Blecker, C. (2013). Effects of Processing on the Compositions and Physicochemical Properties of Fibre Concentrate from Cooked Fruit Pomaces. Food and Bioprocess Technology, 7, 749-760.

Rabetafika, H. N., Bchir, B., Blecker, C., Paquot, M., \& Wathelet, B. (2014). Comparative study of alkaline extraction process of hemicelluloses from pear pomace. Biomass and Bioenergy, 61, 254-264.

Ralet, M.-C., Crépeau, M.-J., Buchholt, H.-C., \& Thibault, J.-F. (2003). Polyelectrolyte behaviour and calcium binding properties of sugar beet pectins differing in their degrees of methylation and acetylation. Biochemical Engineering Journal, 16, 191-201.

Rowland, S. P., \& Howley, P. S. (1989). Simplified hydrolysis of cellulose and substituted cellulose: Observations on trifluoroacetic acid hydrolyses. Journal of Applied Polymer Science, 37, 2371-2382.

Sena Neto, A. R., Araujo, M. A. M., Souza, F. V. D., Mattoso, L. H. C., \& Marconcini, J. M. (2013). Characterization and comparative evaluation of thermal, structural, chemical, mechanical and morphological properties of six pineapple leaf fiber varieties for use in composites. Industrial crops and products, 43, 529537.

Struck, S., Plaza, M., Turner, C., \& Rohm, H. (2016). Berry pomace - A review of processing and chemical analysis of its polyphenols. International Journal of Food Science and Technology, 51, 1305-1318.

Sun, S. L., Wen, J. L., Ma, M. G., \& Sun, R. C. (2013). Successive alkali extraction and structural characterization of hemicelluloses from sweet sorghum stem. Carbohydr Polym, 92, 2224-2231.

Valiente, C., Arrigoni, E., Esteban, R. M., \& Amado, R. (1995). Grape Pomace as a Potential Food Fiber. Journal of Food Science, 60, 818-820.

Vergara-Valencia, N., Granados-Pérez, E., Agama-Acevedo, E., Tovar, J., Ruales, J., \& Bello-Pérez, L. A. (2007). Fibre concentrate from mango fruit: Characterization, associated antioxidant capacity and application as a bakery product ingredient. LWT - Food Science and Technology, 40, 722-729.

Wang, T., Yang, H., Kubicki, J. D., \& Hong, M. (2016). Cellulose Structural Polymorphism in Plant Primary Cell Walls Investigated by High-Field 2D Solid-State NMR Spectroscopy and Density Functional Theory Calculations. Biomacromolecules, 17, 2210-2222.

Wawer, I., Wolniak, M., \& Paradowska, K. (2006). Solid state NMR study of dietary fiber powders from aronia, bilberry, black currant and apple. Solid State Nucl Magn Reson, 30, 106-113.

Xu, C., Leppanen, A. S., Eklund, P., Holmlund, P., Sjoholm, R., Sundberg, K., \& Willfor, S. (2010). Acetylation and characterization of spruce (Picea abies) galactoglucomannans. Carbohydr Res, 345, 810-816. 
Yapo, B. M., \& Koffi, K. L. (2008). The polysaccharide composition of yellow passion fruit rind cell wall: chemical and macromolecular features of extracted pectins and hemicellulosic polysaccharides. Journal of the Science of Food and Agriculture, 88, 2125-2133.

Zhang, P., Dong, S.-J., Ma, H.-H., Zhang, B.-X., Wang, Y.-F., \& Hu, X.-M. (2015). Fractionation of corn stover into cellulose, hemicellulose and lignin using a series of ionic liquids. Industrial crops and products, 76, 688-696.

Rohm H., Brennan C. S., Turner C., Günther E., Campbell G. M., Hernando I., Struck S., Kontogiorgos V. (2015). "Adding value to fruit processing waste: Innovative ways to incorporate fibers from berry pomace in baked and extruded cerealbased foods - A SUSFOOD project." Foods 4(4), 690-697.

Quiles A., Campbell G. M., Struck S., Rohm H. and Hernando I. (2016). "Fiber from fruit pomace: A review of applications in cereal-based products." Food Reviews International, 34 (2), 162-181. 